\title{
Slow Death of Postnatal Hippocampal Neurons by GABA Receptor Overactivation
}

\author{
Wanyan Xu, ${ }^{1}$ Robert Cormier, ${ }^{1}$ Tao Fu, ${ }^{1}$ Douglas F. Covey, ${ }^{2}$ Keith E. Isenberg, ${ }^{1}$ Charles F. Zorumski, ${ }^{1,3}$ and \\ Steven Mennerick ${ }^{1,3}$
}

Departments of ${ }^{1}$ Psychiatry, ${ }^{2}$ Molecular Biology and Pharmacology, and ${ }^{3}$ Anatomy and Neurobiology, Washington

University School of Medicine, St. Louis, Missouri 63110

Neurotransmitters can have both toxic and trophic functions in addition to their role in neural signaling. Surprisingly, chronic blockade of $\mathrm{GABA}_{\mathrm{A}}$ receptor activity for 5-8 d in vitro enhanced survival of hippocampal neurons, suggesting that $\mathrm{GABA}_{\mathrm{A}}$ receptor overactivation may be neurotoxic. Potentiating $\mathrm{GABA}_{\mathrm{A}}$ receptor activity by chronic treatment with the endogenous neurosteroid $(3 \alpha, 5 \alpha)$-3-hydroxypregnan-20-one caused massive cell loss over 1 week in culture. Other potentiators of $\mathrm{GABA}_{\mathrm{A}}$ receptors, including benzodiazepines, mimicked the cell loss, suggesting that potentiating endogenous GABA activity is sufficient to produce neuronal death. Neurosteroid- treated neurons had lower resting intracellular calcium levels than control cells and produced smaller calcium rises in response to depolarizing challenges. Manipulating intracellular calcium levels with chronic elevated extracellular potassium or with the calcium channel agonist Bay K 8644 protected neurons. The results may have implications for the mechanisms of programmed cell death in the developing CNS as well as implications for the long-term consequences of chronic GABAmimetic drug use during development.

Key words: GABA; calcium; toxicity; apoptosis; benzodiazepine; neurosteroid
Neurotransmitters can have acute or chronic toxic effects on neurons in addition to roles in moment to moment signaling. A particularly well studied example is the neurotransmitter glutamate, which through excessive activation of postsynaptic receptors can initiate necrotic and apoptotic neuronal death (Ankarcrona, 1998; Michaelis, 1998) In many cases, glutamate receptor overactivation and resultant death are associated with pathological increases in intracellular calcium (Choi, 1995).

A potential role for other neurotransmitters, particularly inhibitory neurotransmitters, in mediating either normal or pathological neuronal death is unclear. Recent results suggest a rapid neuronal death is elicited by chloride flux through $\mathrm{GABA}_{\mathrm{A}}$ and glycine receptors in embryonic retina (Chen et al., 1998) and that a component of the acute swelling of dendrites in response to insults is blocked by $\mathrm{GABA}_{\mathrm{A}}$ receptor antagonists (Hasbani et al., 1998). Also, fetal forebrain GABAergic neurons are susceptible to death by treatment with GABA agonists (Honegger et al., 1998). These more recent observations coupled with aforementioned excitotoxicity suggest that proper balance between excitation and inhibition may be critical to cell survival in the CNS and that overinhibition, like overexcitation, may be toxic.

We investigated the possibility that the primary inhibitory brain neurotransmitter GABA is neurotoxic. We examined this hypothesis in the context of studies of neurosteroid-mediated enhancement of GABAergic neurotransmission (Wittmer et al.,

Received Nov. 24, 1999; revised Feb. 1, 2000; accepted Feb. 22, 2000.

This work was supported by National Institutes of Health Grants GM47969 (C.F.Z. and D.F.C.) and MH45493 (C.F.Z.) and a National Alliance for Research on Schizophrenia and Depression Young Investigator Award (S.M.). We thank Ann Benz for technical assistance.

W.X. and R.C. contributed equally to this work.

Correspondence should be addressed to Dr. Steven Mennerick, Department of Psychiatry, Washington University School of Medicine, 4940 Children's Place, St. Louis, MO 63110. E-mail: menneris@psychiatry.wustl.edu.

Copyright (C) 2000 Society for Neuroscience $0270-6474 / 00 / 203147-10 \$ 15.00 / 0$
1996; Zorumski et al., 1998). Neurosteroids are progesterone and deoxycorticosterone metabolites produced in the CNS and periphery that are putative endogenous modulators of $\mathrm{GABA}_{\mathrm{A}}$ receptors (Majewska et al., 1986; Majewska, 1992). Of particular interest clinically have been neurosteroids that positively modulate the $\mathrm{GABA}_{\mathrm{A}}$ receptor, because these compounds, administered exogenously, are effective anesthetics, anticonvulsants, and anxiolytics (Majewska, 1992; Lambert et al., 1995). Of many known modulators of $\mathrm{GABA}_{\mathrm{A}}$ receptors, neurosteroids are the clearest example of an endogenous substance capable of altering GABA receptor activity.

Our results show that excessive $\mathrm{GABA}_{\mathrm{A}}$ receptor activation initiates a slow form of neuronal death in cultured hippocampal neurons. The death is slow whether immature or mature synaptic networks are present, is not caused by direct or indirect excitotoxic mechanisms, and may be related to depressed intracellular calcium levels. The results are potentially relevant to diseases of the nervous system, to normal developmental neuronal death, and to the chronic effects of abused and therapeutic GABAmimetic drugs on the developing nervous system.

\section{MATERIALS AND METHODS}

Hippocampal cultures. Hippocampal cells were harvested from albino postnatal rats (days 1-3) and dissociated by papain and mechanical dispersion as previously described (Yang et al., 1993). Cells were seeded on the bottom of a collagen-coated culture dish at an initial plating density of $2.1 \times 10^{3} / \mathrm{mm}^{2}$, except for experiments shown in Figure $8, E$ and $F$, in which cells were seeded at $0.7 \times 10^{3} / \mathrm{mm}^{2}$. Culture medium consisted of Eagle's medium (Life Technologies, Gaithersburg, MD) supplemented with heat-inactivated horse serum (5\%), fetal calf serum (5\%; Life Technologies), $17 \mathrm{~mm}$ D-glucose, $400 \mu \mathrm{M}$ glutamine, $50 \mathrm{U} / \mathrm{ml}$ penicillin, and $50 \mu \mathrm{g} / \mathrm{ml}$ streptomycin. Cell cultures were prepared on 35 $\mathrm{mm}$ plastic culture dishes (Falcon) for toxicity and electrophysiology experiments and on glass coverslips for imaging experiments. Cytosine arabinoside $(10 \mu \mathrm{M})$ was added on the third to fourth day in vitro (DIV 3-4). Treatment protocols were begun on DIV 3 or 4 , and cell counts 
were performed on DIV 8-12, except for time course experiments (see Fig. 2A).

For cell counts, phase-bright neuron cell bodies present within the field of a $20 \times$ microscope objective were counted and recorded. This procedure allowed multiple assessments of the same plate. In some platings, clusters of neuronal cell bodies were present (e.g., Fig. 1), leading to concerns about the accuracy of counts. To determine the amount of error, control plates containing clustered cell bodies were fixed with $4 \%$ paraformaldehyde and stained with Hoechst 33342. Cell counts of phasebright neurons were compared with nuclear counts of the same cluster under epifluorescence. The counts of phase-bright cell bodies were within $1.3 \pm 3 \%$ of the nuclear counts (average cluster size, $8.8 \pm 0.8$ neurons; $n=8$ clusters). We thus did not make correction for errors in counting attributable to clustering of neuronal cell bodies.

All experiments were performed on at least three independent platings of cells. Counts from 5-15 fields from an individual plating were used to generate an average cell count for each experimental condition from a single plating. In several experiments $(n=5)$, an observer blinded to experimental conditions performed the cell counts. This had no effect on quantification. To account for plating-to-plating differences in cell density, the average counts of experimental groups were averaged and normalized to the control (untreated) group from the same plating. Comparative statistics were performed on these normalized values (vs control) using an independent, two-tailed $t$ test. Significant differences are were taken as $p<0.05$

Drugs and reagents. All drugs and chemicals were from Sigma (St. Louis, MO). (3 $\alpha, 5 \alpha)$-3-Hydroxypregnan-20-one (DHP) and lorazepam were prepared in DMSO as concentrated stock solutions. The final concentration of DMSO in cultures was $\leq 0.1 \%$. Bay K 8644 stock was prepared in methanol and diluted 1:1000 into culture medium. Other drugs were prepared as a concentrated stock in water and were diluted 1:200-1:1000. Control experiments showed that neither DMSO nor methanol at the concentrations used affected cell survival (data not shown).

Electrophysiology. Whole-cell patch-clamp recordings were performed on control or treated neurons at DIV 8-10 (5-7 d after treatment was begun). Culture medium was exchanged for an extracellular recording solution containing (in $\mathrm{mM}$ ) $\mathrm{NaCl}(140), \mathrm{KCl}(4), \mathrm{HEPES}$ (10), $\mathrm{CaCl}_{2}$ (2.0), $\mathrm{MgCl}_{2}$ (1.0), glucose (10), and HEPES (10), $\mathrm{pH}$ 7.25. The wholecell pipette solution contained (in $\mathrm{mM}$ ) Cs methane sulfonate (140) or $\mathrm{CsCl}$ (140), $\mathrm{NaCl}(4), \mathrm{CaCl}_{2}$ (0.5), EGTA (5), and HEPES (10), $\mathrm{pH} 7.25$. Data were collected using commercially available software (Pclamp 6.0; Axon Instruments, Foster City, CA) controlling an Axopatch 1-D patchclamp amplifier (Axon Instruments) via a Digidata 1200 acquisition board. Whole-cell current in response to voltage ramps $(1.14 \mathrm{~V} / \mathrm{sec})$ in the absence of GABA was subtracted from current in the presence of GABA to generate GABA current-voltage curves (see Fig. 6).

Xenopus oocytes. For experiments examining DHP concentrations in conditioned medium (Fig. 2C), a bioassay was developed using Xenopus oocytes expressing recombinant $\mathrm{GABA}_{\mathrm{A}}$ receptors. cRNAs encoding the $\alpha 1, \beta 2$, and $\gamma 2 \mathrm{~L}$ subunits were obtained by in vitro transcription (mMessage mMachine; Ambion, Austin, TX) from linearized plasmids and were injected into the cytoplasm of stage V-VI oocytes. Two to $7 \mathrm{~d}$ after injection, oocytes were placed into a chamber containing $100 \mu 1$ of ND96 medium. ND96 contained (in $\mathrm{mM}$ ) $\mathrm{NaCl}$ (96), $\mathrm{KCl}$ (2.5), $\mathrm{CaCl}_{2}$ (1.8), $\mathrm{MgCl}_{2}$ (1.0), and HEPES (10), $\mathrm{pH} 7.4$. Oocytes were voltage clamped at $-50 \mathrm{mV}$ with a two-electrode voltage-clamp configuration, and solutions containing GABA and dilute culture medium were applied to the oocytes via a multibarrel pipette. The steady-state current in response to each solution was measured and recorded using an Axoclamp 2-B amplifier and Pclamp software.

Calcium imaging. Calcium imaging was performed on cultures at DIV 8-10 (days 5-7 after GABAmimetic treatment). The culture medium was exchanged for an extracellular recording solution with $5 \mu \mathrm{M}$ fura-2 AM for $45 \mathrm{~min}$ at $37^{\circ} \mathrm{C}$, after which fura-2 AM was washed away with fresh recording medium. Cells were returned to $37^{\circ} \mathrm{C}$ for an additional $45 \mathrm{~min}$ to allow AM cleavage. Cells were then imaged using a Nikon (Melville, NY) Eclipse inverted microscope equipped with a filter wheel (Sutter Instruments, Novato, CA) and an intensified CCD camera (PTI, Monmouth, NJ) interfaced to a frame grabber (Scion, Frederick, MD) and Pentium II computer. Data were collected at room temperature in extracellular recording solution and were analyzed using custom software. Raw data are presented as ratios of fluorescence in response to illumination at 340 and $380 \mathrm{~nm}$. In vitro calibrations (Grynkiewicz et al., 1985) suggested that these ratios correspond to resting calcium levels of
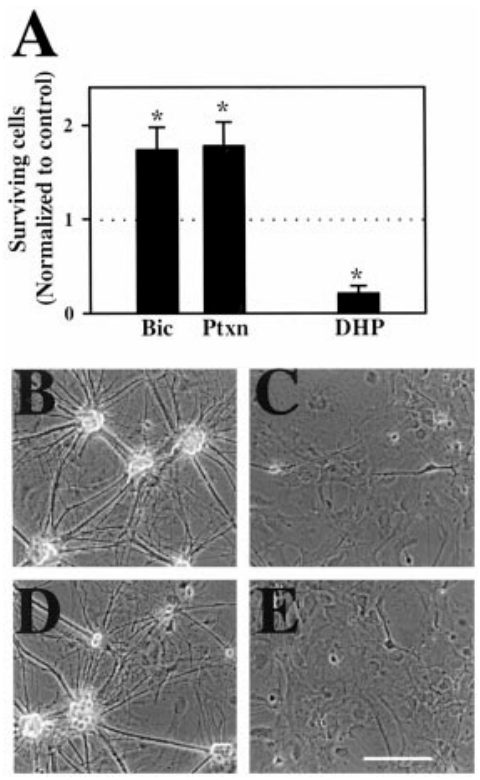

Figure 1. Prevention and exacerbation of neuronal death by manipulating GABA $_{\mathrm{A}}$ receptors. $A$, Cell survival at DIV 10-12 assessed by cell counts of randomly selected microscopic fields after chronic treatment begun at DIV 4 with $50 \mu \mathrm{M}$ bicuculline (Bic; $n=13$ platings; $p<0.05$ ) or with $10 \mu \mathrm{M}$ picrotoxinin (Ptxn; $n=10$ platings; $p<0.05)$. The $\mathrm{GABA}_{\mathrm{A}}$ potentiating neurosteroid DHP $(3 \mu \mathrm{M})$ depressed cell numbers evaluated at DIV $10-13$ ( $p<0.05 ; n=6$ platings) Counts in this and subsequent figures are expressed normalized to counts of control cultures from the same plating. The dotted line in this and subsequent graphs denotes the normalized control counts (1.0). $B-E$, Photomicrographs of control postnatal hippocampal cultures $(B)$ and cultures treated with $3 \mu \mathrm{M}$ DHP $(C-E)$. The photographs were obtained at DIV 13. Treatments were begun at DIV 4. $C$, Photomicrograph from a culture treated with $3 \mu \mathrm{M}$ DHP alone. $D$, Cells treated with DHP and $50 \mu \mathrm{M}$ bicuculline. $E$, Cells treated with $3 \mu \mathrm{M}$ DHP and $0.1 \mu \mathrm{M}$ RU486. Scale bar, $130 \mu \mathrm{m}$ (applies to $B-E)$.

$<50 \mathrm{~nm}$ in control cultures. Experiments on fura-2 AM-loaded cells were repeated on at least three independent platings of cells except where noted.

\section{RESULTS}

We probed the chronic effects of blocking $\mathrm{GABA}_{\mathrm{A}}$ receptors in cultures of postnatal hippocampal cells containing both GABAergic and glutamatergic neurons, as well as an underlyling monolayer of astrocytes. Over the course of the first $10 \mathrm{~d}$ in these cultures, neurons decrease in number by $\sim 60-80 \%$, similar to observations made in other culture systems (D’Mello et al., 1993). Treatment of cultures on DIV 4 with $10 \mu \mathrm{M}$ picrotoxinin, a noncompetitive $\mathrm{GABA}_{\mathrm{A}}$ receptor antagonist, or with $50 \mu \mathrm{M}$ bicuculline, a competitive antagonist, revealed that a percentage of the neuronal death was prevented by blocking $\mathrm{GABA}_{\mathrm{A}}$ receptors (Fig. 1A). Die-off still occurred in antagonist-treated cultures (data not shown), but compared with untreated control cultures from the same plating, both antagonists produced a statistically significant increase in neuron numbers over control cultures (Fig. $1 A$ ). This result suggests that activation of $\mathrm{GABA}_{\mathrm{A}}$ receptors plays a detectable role in neuronal death of cultured hippocampal neurons.

\section{Neurosteroids enhance neuronal death by a GABAergic mechanism}

Given the suggestion in these initial experiments that activation of $\mathrm{GABA}_{\mathrm{A}}$ receptors is involved in a fraction of neuronal death in 
culture, we examined whether positive modulators of $\mathrm{GABA}_{\mathrm{A}}$ receptors might potentiate neuronal death in cultures. We began our studies by examining the effect of the $\mathrm{GABA}_{\mathrm{A}}$-potentiating neurosteroid DHP on neuronal survival. We administered DHP at a concentration of $3 \mu \mathrm{M}$ either in three treatments of $1 \mu \mathrm{M}$ at DIV 3, 5, and 7 or in a bolus at DIV 3. Both treatment protocols yielded a similar profile of neuronal death when cultures were examined on DIV 10-12 (Fig. 1A-E). Neurons remaining after DHP-induced death were usually small cells, with limited neuritic arbors (Fig. 1C,E; see Figs. 3, 4, 8, 9). The underlying monolayer of astrocytes was not detectably altered by chronic DHP treatment (Fig. $1 B-E$ ).

To test the hypothesis that $\mathrm{GABA}_{\mathrm{A}}$ receptors are involved in neurosteroid-induced neuronal death, we examined the effect of $\mathrm{GABA}_{\mathrm{A}}$ receptor antagonists on death induced by DHP. Consistent with a pivotal role for $\mathrm{GABA}_{\mathrm{A}}$ receptors in mediating the slow neuronal death, bicuculline $(50 \mu \mathrm{M})$ completely blocked the death caused by chronic treatment with $3 \mu \mathrm{M}$ DHP (Fig. $1 B-E$ ). In nine experiments, neuron numbers in DHP-treated cultures were reduced by $82 \pm 6 \%$ when counted at DIV 10-12, but numbers were $177 \pm 42 \%$ ( $n=6$ experiments) and $120 \pm 18 \%$ ( $n=8$ experiments) of control when DHP was co-administered with picrotoxinin and bicuculline, respectively. In contrast, the antiapoptotic, genomic steroid receptor antagonist RU486 did not affect the neuronal death (Fig. $1 E ; n=3$ experiments).

During the period of DHP treatment, neuronal loss usually began at approximately DIV 7, even when DHP was administered as a bolus on DIV 4 (Fig. $2 A$ ). DHP-induced neuronal death was concentration-dependent, with an $\mathrm{EC}_{50}$ of $1.1 \mu \mathrm{M}$, obtained by fitting the data in Figure $2 B$ to the Hill equation. This concentration dependence approximately parallels the acute effects of DHP on GABA-mediated synaptic currents observed in previous studies (Zorumski et al., 1998; Fig. 2B). The concentration-response relationship was apparently not affected by steroid metabolism. The diluted hydrophobic fraction of conditioned medium from cells treated with DHP for 1 week produced a similar potentiation of $\mathrm{GABA}_{\mathrm{A}}$ responses in Xenopus oocytes heterologously expressing $\mathrm{GABA}_{\mathrm{A}}$ receptors as $3 \mu \mathrm{M}$ DHP added freshly to unconditioned culture medium (Fig. 2C). Fractionated conditioned culture medium with no exogenous DHP added had negligible effects on GABA responses in oocytes (Fig. $2 C$ ), suggesting that global levels of $\mathrm{GABA}_{\mathrm{A}}$-potentiating endogenous neurosteroids in these cultures are negligible.

Because a primary action of DHP is to potentiate endogenous GABA actions, we reasoned that the slow time course of neuronal death may be related to the immature state of synaptic networks during the first few days of the treatment regimen (Yang et al., 1993). To test this idea, we treated cells with $3 \mu \mathrm{M}$ DHP beginning at DIV 7 rather than the typical DIV 3 and examined the progression of neuronal death. As shown in Figure 3, progression of death was still slow, proceeding gradually over 3-7 d in culture. However, neuronal death was faster than when the same treatment regimen was applied beginning at DIV 3 (compare Fig. $2 A$ ), suggesting that some aspect of cell maturity, possibly synaptic maturity, may play a role in the protracted time course of neuronal death in the early treatment protocol.

\section{Endogenous GABA activity is sufficient for GABA toxicity}

Positive neurosteroid modulators of $\mathrm{GABA}_{\mathrm{A}}$ receptors both potentiate endogenous GABA actions and, at sufficiently high concentrations, directly activate the $\mathrm{GABA}_{\mathrm{A}}$ receptor in the absence
A

B
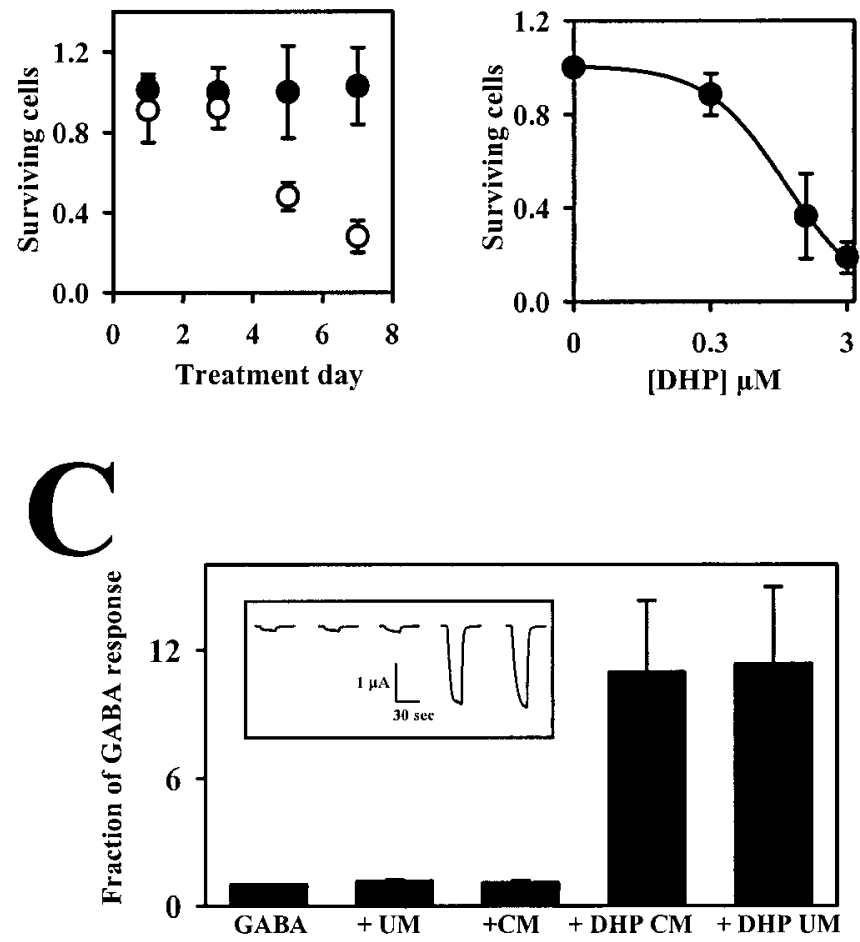

Figure 2. Time course and concentration dependence of DHP-mediated neuronal death. $A$, The graph represents one experiment in which cell counts were made at sequential time points during DHP treatment. Counts of DHP-treated cultures were significantly different from control cultures at DIV 8 and 10 (treatment days 5 and 7). In the graph, counts of individual microscopic fields, including those of control dishes, were expressed relative to the mean control counts; thus both control and experimental treatment groups show error bars. $B$, The graph represents the effects of treatment of cultures with $0.3,1.5$, and 3.0 $\mu \mathrm{M}$ DHP. Cell counts were obtained at DIV 10. $C$, Lack of metabolism of steroids in culture. A bioassay was used to determine the amount of steroid remaining in cultures $10 \mathrm{~d}$ after treatment. Conditioned medium $(C M)$ from DIV 14 cultures was harvested from untreated cultures or cultures treated with $3 \mu \mathrm{M}$ DHP. Unconditioned medium (UM) was used as a comparison and was either spiked immediately before use with $3 \mu \mathrm{M}$ DHP $(+D H P)$ or left untreated. For all samples, hydrophobic steroids were separated from hydrophilic molecules using a Baker 10 SPE octadecyl column. The hydrophobic fraction was eluted with methanol, dried, and resuspended in Xenopus oocyte recording medium to a final predicted concentration of 1 $\mu \mathrm{M}$ DHP for the DHP-treated samples (assuming no degradation in the conditioned medium samples). This final concentration of DHP $(1 \mu \mathrm{M})$ was used for evaluation because it is near the $\mathrm{EC}_{50}$ for modulation of $\mathrm{GABA}_{\mathrm{A}}$ receptors (Zorumski et al., 1998). GABA $(1 \mu \mathrm{M})$ was added to each of the reconstituted samples. Solutions containing GABA alone or the diluted culture medium were applied to voltage-clamped Xenopus oocytes. The amplitudes of responses to each solution are expressed relative to the response to GABA alone in the bar graph. Inset, Raw traces from a representative oocyte. Experimental conditions for the inset are in the order shown on the bar graph.

of GABA. We tested whether potentiation of endogenous GABA activity is sufficient to trigger toxicity by examining the effects of a benzodiazepine, a class of positive modulators that does not directly activate the $\mathrm{GABA}_{\mathrm{A}}$ receptor (Macdonald and Olsen, 1994). Lorazepam (1-10 $\mu \mathrm{M})$ administered at DIV 3 triggered a slow death similar in time course and cell appearance to that triggered by DHP (Fig. 4A,B,D,E). The death was completely 

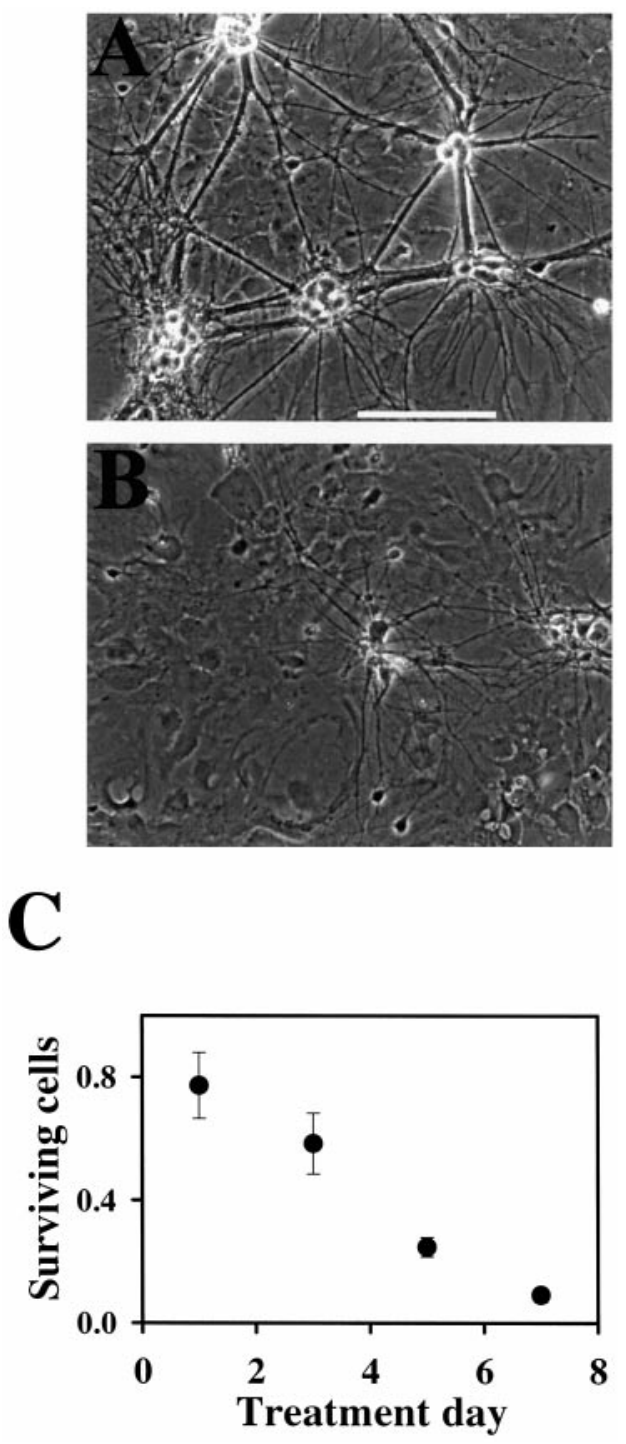

Figure 3. Late treatment with neurosteroid also promotes slow neuronal death. $A, B$, Photomicrographs (DIV 14) of hippocampal cultures treated with vehicle $(A)$ or with $3 \mu \mathrm{M}$ DHP beginning on DIV 7 rather than the usual DIV 4. Scale bar, $130 \mu \mathrm{m}$. $C$, Time course of neuronal death when cells were acutely treated $3 \mu \mathrm{M}$ DHP at DIV 7. Each point represents 15-21 microscopic fields.

prevented by the $\mathrm{GABA}_{\mathrm{A}}$ receptor antagonist bicuculline $(50 \mu \mathrm{M})$ co-administered with lorazepam (Fig. $4 D-F$ ). In four experiments, $10 \mu \mathrm{M}$ lorazepam depressed cell numbers by $78 \pm 4 \%$ $(p<0.05)$, and bicuculline reversed the effect to within $5 \pm 20 \%$ of control $(p>0.05)$. The barbiturate pentobarbital $(50 \mu \mathrm{M})$ also elicited neuronal death (Fig. $4 C ; 70 \pm 10 \%$ depression of cell numbers; $p<0.05 ; n=4$ platings), as did the direct agonist muscimol (see below). These results suggest that potentiation of endogenous GABA activity is sufficient to trigger neuronal death and that direct activation of $\mathrm{GABA}_{\mathrm{A}}$ receptor with exogenous agonists is also toxic.

\section{GABA-mediated neuronal death does not result from excitotoxicity}

Although GABA is the most widespread inhibitory neurotransmitter in the mature nervous system, in many immature systems, $\mathrm{GABA}_{\mathrm{A}}$ receptor activation is excitatory by virtue of a diminished
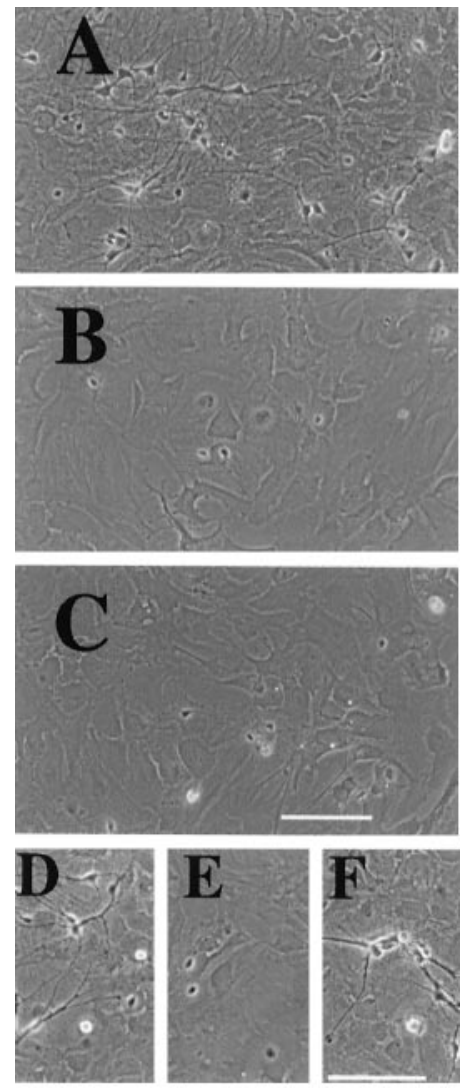

Figure 4. Other potentiators of GABA actions at $\mathrm{GABA}_{\mathrm{A}}$ receptors also cause slow neuronal death. $A-C$ are from one plating; $D-F$ are from another plating. $A$, Control culture. $B$, Lorazepam $(10 \mu \mathrm{M})$. $C$, Pentobarbital $(50 \mu \mathrm{M}) . D$, Culture treated with bicuculline $(50 \mu \mathrm{M})$ alone. $E$, Lorazepam $(5 \mu \mathrm{M}) . F$, Culture treated with $5 \mu \mathrm{M}$ lorazepam plus $50 \mu \mathrm{M}$ bicuculline. Photomicrographs were obtained at DIV 10-11, and treatments were begun at DIV 4. Scale bars, $130 \mu \mathrm{m}$ (bar in $C$ applies to $A-C$; bar in $F$ applies to $D-F$ ).

chloride gradient across the neuronal plasma membrane (Cherubini et al., 1990; Leinekugel et al., 1999). We considered the hypothesis that if GABA is excitatory in postnatal hippocampal cultures, potentiation of GABA actions may increase network activity, causing excessive glutamate receptor activation and resultant excitotoxicity. Alternatively, GABA, if excitatory, may promote the influx of calcium through voltage-gated calcium channels, thus directly triggering calcium-dependent excitotoxicity.

We performed several experiments to test whether $\mathrm{GABA}_{\mathrm{A}}$ receptor-mediated excitation may underlie GABA toxicity. First, we examined intracellular calcium responses to exogenous GABA applications. After preloading with $5 \mu \mathrm{M}$ fura-2 AM in the bath solution, neither control nor DHP-treated neurons (DIV 7) responded with significant calcium rises when challenged with 100 $\mu \mathrm{M}$ GABA (Fig. 5). In the same cells, however, NMDA elicited robust calcium rises (Fig. 5). As an additional positive control, neurons loaded with $140 \mathrm{~mm} \mathrm{KCl}$ through a whole-cell recording pipette that also contained $60 \mu \mathrm{M}$ fura-2 responded with clear intracellular $\left[\mathrm{Ca}^{2+}\right]$ increases in response to $100 \mu \mathrm{M}$ GABA challenge (Fig. 5C,D). GABA challenges to untreated and DHPtreated cultures were repeated on three independent platings of neurons; in none of the experiments did neurons respond to GABA applications with $\mathrm{Ca}^{2+}$ increases.

In independent experiments, we examined the reversal poten- 
A

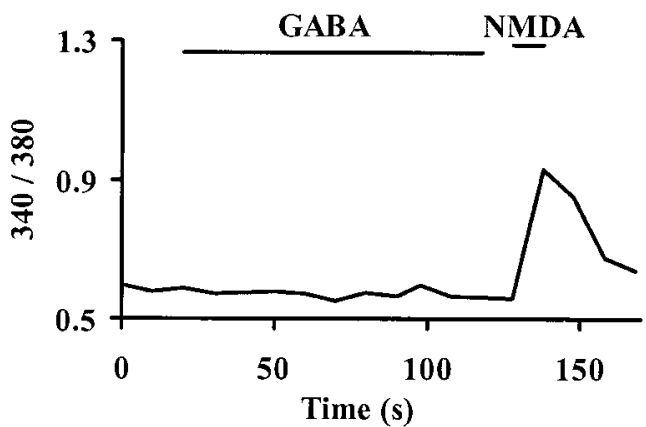

B

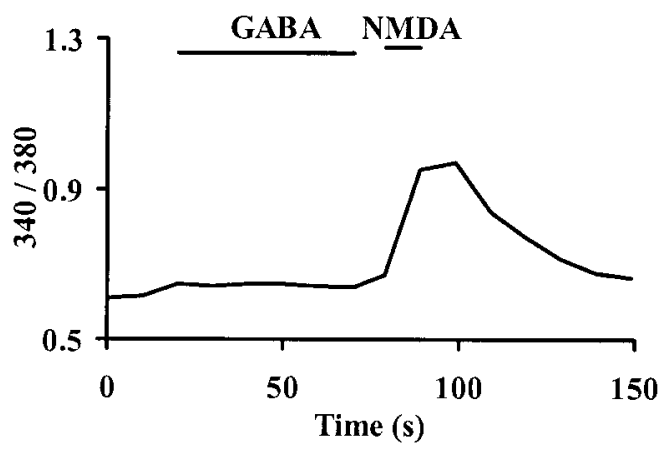

r

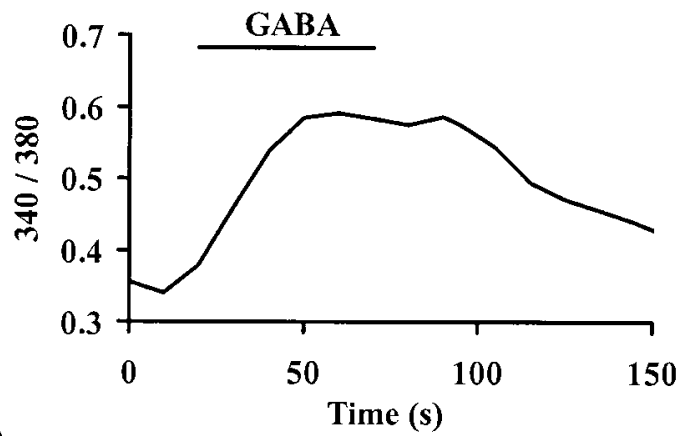

D

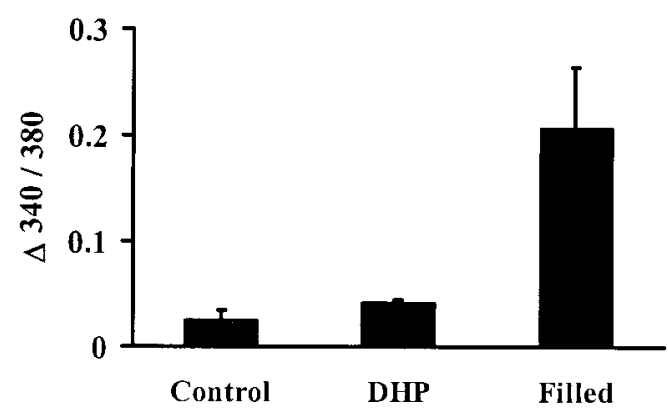

Figure 5. Intracellular calcium responses suggest that GABA is not excitatory. $A-C$, Calcium rises were measured in response to $100 \mu \mathrm{M}$ GABA applied by local perfusion to cultured neurons at DIV 8-10. Raw traces represent ratiometric Fura-2 images from a control neuron $(A)$, DHP-treated neuron $(B)$, and a control neuron loaded with $140 \mathrm{~mm}$ chloride $(C)$ using a whole-cell recording pipette. In $A$ and $B$, cells were also challenged with $300 \mu \mathrm{M}$ NMDA in extracellular saline containing no tial of GABA currents using whole-cell electrophysiological recording techniques. Initial experiments with gramicidin perforated patch recordings suggested that in our hands this technique was not reliable for obtaining good electrical access to hippocampal neurons. Therefore, we adopted an alternative strategy to estimate the endogenous reversal potential of $\mathrm{GABA}_{\mathrm{A}}$ currents. For these experiments, we used patch pipettes that were sharper than typical whole-cell pipettes $(8-12 \mathrm{M} \Omega$ ) to slow the diff usion of the recording solution into the cell, and we performed ramp depolarizations to obtain a GABA current-voltage curve immediately on membrane rupture, when the cytoplasm should still be relatively intact (Fig. 6). When $140 \mathrm{~mm} \mathrm{KCl}$ was used in the intracellular solution, the initial GABA current-voltage curve exhibited a reversal potential of $-55 \pm 5 \mathrm{mV}(n=14$ neurons in three independent platings evaluated at DIV 9-10). After $30 \mathrm{sec}$ of intracellular perfusion with the pipette solution, this value was shifted toward $0 \mathrm{mV}$, to $-25 \pm 2 \mathrm{mV}$, as expected by the nearly symmetrical chloride concentrations of the pipette and extracellular solutions. The negative GABA reversal potential pertained to both control and DHP-treated cells $(-55 \pm 5 \mathrm{mV} ; n=16$ DHP-treated neurons in three different platings evaluated 5-6 d after DHP treatment; Fig. 6).

In a final experiment to test involvement of excitotoxicity in neurosteroid-mediated neuronal death, we examined the effect of the AMPA receptor antagonist NBQX $(1 \mu \mathrm{M})$ and the NMDA receptor antagonist D-APV $(50 \mu \mathrm{M})$ on DHP-induced neuronal death. A clear interpretation of these results was precluded by enhanced neuronal death in the presence of APV or NBQX alone. Cell numbers evaluated at DIV 10-12 were reduced by $40-60 \%$ by APV and NBQX ( $n=3$ experiments). These results are consistent with recent suggestions of induction of apoptosis by NMDA receptor antagonists (Hwang et al., 1999; Ikonomidou et al., 1999) and are consistent with the idea that overinhibition causes slow death of hippocampal neurons.

\section{Evidence that low basal intracellular calcium may trigger GABA-mediated neuronal death}

Elevating intracellular calcium concentration protects neurons in several models of neuronal death (D'Mello et al., 1993; Deshmukh and Johnson, 1997). We therefore tested the idea that overactivation of $\mathrm{GABA}_{\mathrm{A}}$ receptors may be associated with depressed intracellular calcium concentrations. Consistent with the idea that depressed calcium signals may at least partially underlie the demise of postnatal hippocampal neurons exposed to GABA potentiators, we found that calcium signaling was significantly diminished in DHP-treated cultures (Fig. 7A). We found that, on average, peak $\mathrm{KCl}$-evoked calcium transients measured in the absence of DHP were $41 \pm 11 \%$ of control ( $n=4$ experiments). Significantly depressed $\mathrm{Ca}^{2+}$ signals were observed in each of the four independent experiments. In addition, in four of eight experiments, basal resting $\mathrm{Ca}^{2+}$ levels were significantly lower than control in the DHP-treated cells. In one separate experiment in

added $\mathrm{Mg}^{2+}$ and $5 \mu \mathrm{M}$ glycine to confirm the ability of neurons to respond to excitation with a calcium increase. $D$, Summary of the calcium increases to application of $100 \mu \mathrm{M}$ GABA under the three conditions in $A-C$. Cells were either untreated (Control; $n=35$ cells) or had been treated with DHP on DIV 3 (DHP; $n=37$ ). Positive control data ( filled) came from three neurons filled with $140 \mathrm{mM} \mathrm{KCl}$ in a whole-cell recording pipette containing $60 \mu \mathrm{M}$ fura-2. The data are from one plating but are representative of three independent experiments in which no calcium response from $100 \mu \mathrm{M}$ GABA was observed. 

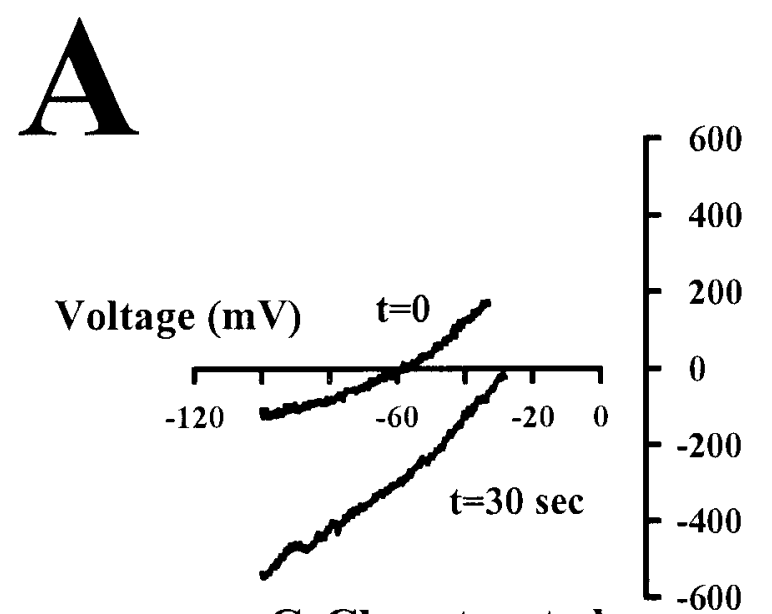

CsCl, untreated
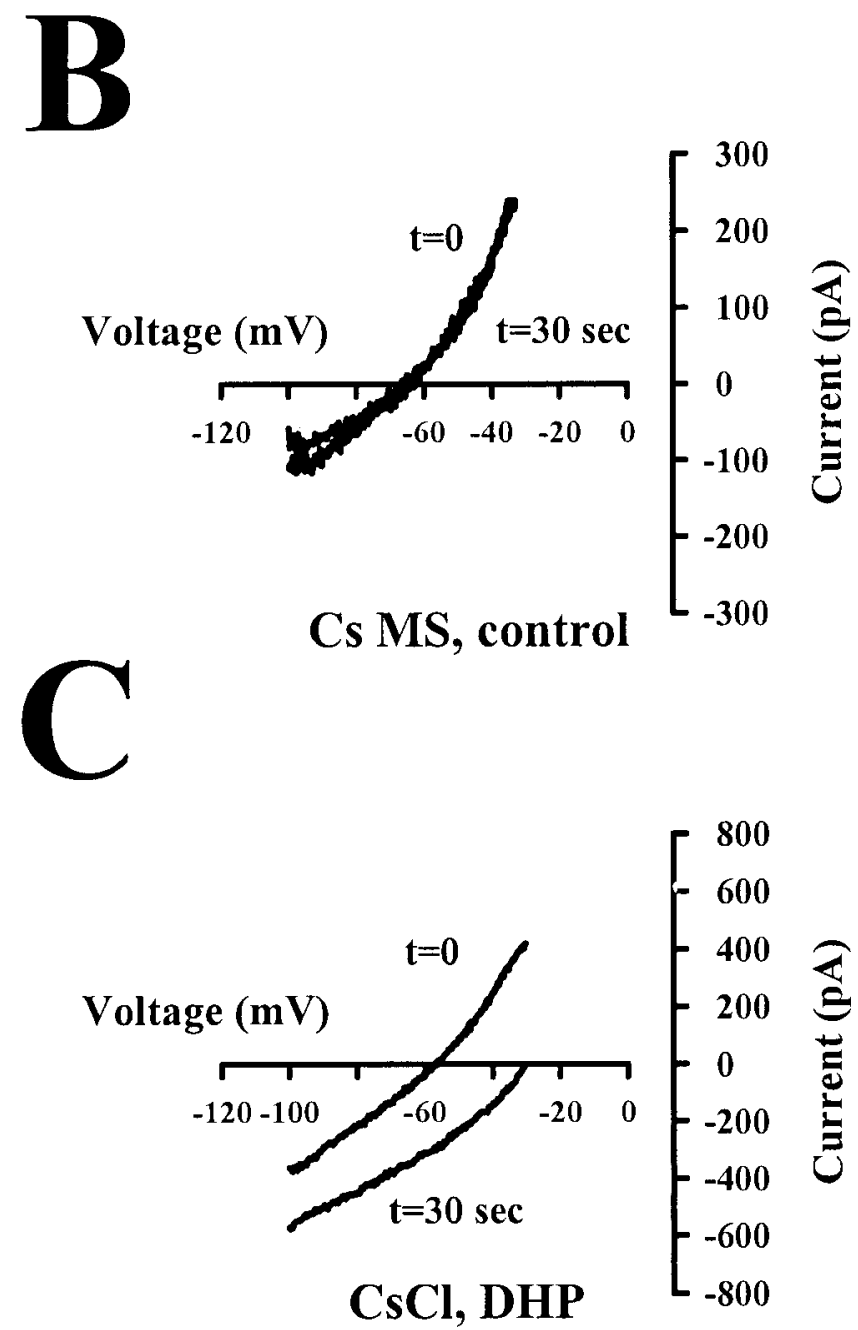

Figure 6. Endogenous GABA reversal potentials suggest GABA is inhibitory in hippocampal cultures. $A$, Example current-voltage curve from an untreated cell at DIV 8 . The curve was generated by subtracting the current response to a voltage ramp in the absence of $0.5 \mu \mathrm{M}$ GABA from the response to the same ramp in the presence of GABA. The protocol was performed immediately on achieving the whole-cell recording mode $(t=0)$ or $30 \mathrm{sec}$ after membrane rupture $(t=30) . B$, The same protocol was performed on another cell but using methane sulfonate as the primary anion in the pipette solution. $C$, The same protocol was performed on a cell from the same plating but treated with DHP for $6 \mathrm{~d}$.
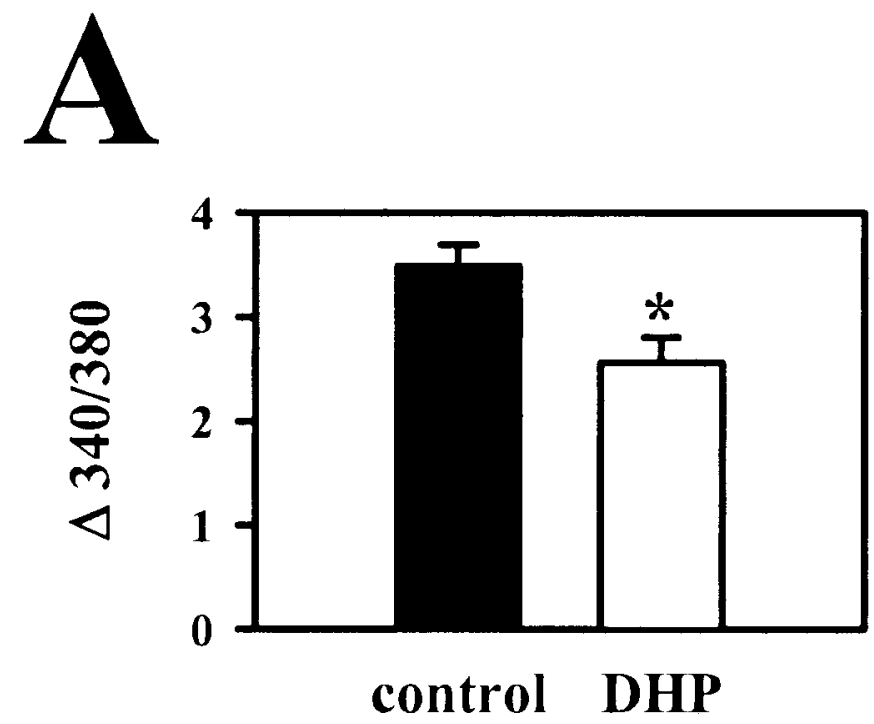

B

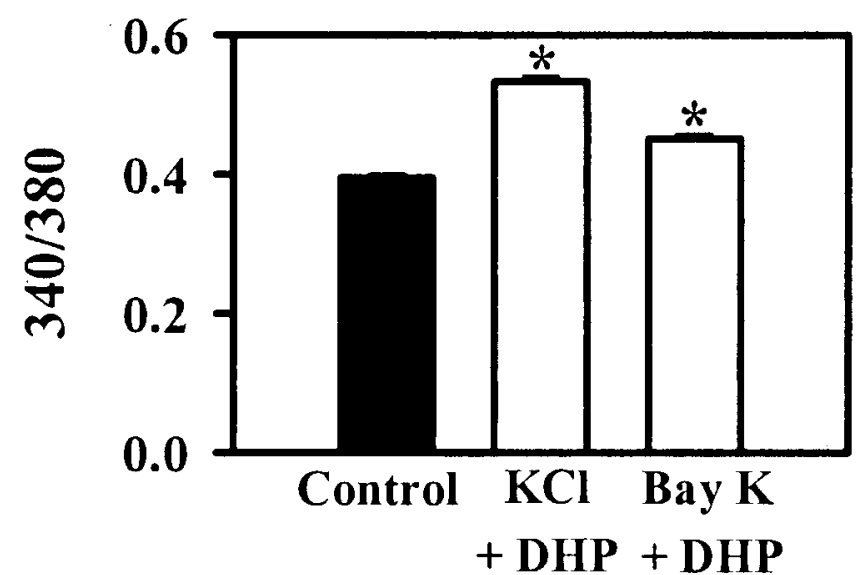

Figure 7. Intracellular $\mathrm{Ca}^{2+}$ and GABAmimetic treatment. $A$, KClevoked transient calcium rises are depressed by chronic DHP treatment. Calcium influx was stimulated with a $30 \mathrm{sec}$ application of $30 \mathrm{~mm} \mathrm{KCl}$. Note that imaging was performed in the absence of DHP on cells $5 \mathrm{~d}$ after initiation of DHP treatment. The depressed change in fluorescence suggests depressed calcium influx in DHP-treated cells (open bar; $n=57$ cells) versus control cells (solid bar; $n=50$ cells). ${ }^{*} p<0.01$. The data represent one experiment from a single plating but are representative of four replications in independent platings. $B$, Calcium is chronically increased by growing cells in the presence of $35 \mathrm{mM} \mathrm{KCl}$ or in the presence of $1.5 \mu \mathrm{M}$ Bay K 8644. Bay K or KCl was added simultaneously with DHP, and imaging was performed $48 \mathrm{hr}$ after treatment $(n=530-914$ cells for each condition, representative of results on four different plates).

which muscimol was used as the toxic agent, $\mathrm{Ca}^{2+}$ responses were significantly blunted, and basal calcium decreased (49 and $62 \%$ of control, respectively, $n=18-19$ cells per condition). These studies demonstrate that chronic overinhibition triggers long-term changes in calcium entry or calcium handling that result in blunted calcium rises in response to depolarizing stimuli. The results are consistent with the idea that depressed intracellular calcium levels may participate in the neuronal death associated with overinhibition, although the experiments do not directly 
address whether decreased $\mathrm{Ca}^{2+}$ signaling is a cause of or an effect of the neuronal death program induced by GABAmimetics.

If depressed intracellular calcium levels are causally related to the demise of hippocampal neurons exposed to GABA potentiators, then it should be possible to rescue cells by elevating intracellular calcium levels. We found that both chronic elevated $\mathrm{KCl}$ (35 mm total) and Bay K $8644(1.5 \mu \mathrm{M})$ effectively elevated intracellular calcium in the presence of a toxic concentration DHP when evaluated 2-6 d after the simultaneous addition of drugs (Fig. 7B; average difference from control was $141 \pm 6 \%$ for $\mathrm{KCl}$ plus DHP and $128 \pm 11 \%$ for Bay K 8644; $p<0.05 ; n=5$ experiments). Therefore, we examined whether these agents could render significant protection against GABAmimetic toxicity.

We grew cultures in $35 \mathrm{~mm}$ extracellular potassium $(30 \mathrm{~mm}$ added to $5 \mathrm{~mm}$ potassium present in the normal medium, coadministered with GABA mimetics) to chronically depolarize cells. Elevated extracellular potassium completely protected neurons from the insult of $3 \mu \mathrm{M}$ DHP or $50 \mu \mathrm{M}$ pentobarbital added at DIV 3-4 (Fig. 8A-F). Elevated potassium treatment also mostly prevented the normal neuronal death in control cultures (Fig. 8). Compared with cultures in which sodium was added as an osmostic control, $30 \mathrm{~mm}$ potassium added at DIV 4 produced a $327 \pm 35 \%$ increase in cell numbers measured at DIV $10-12(n=$ 8 experiments; $p<0.05$ vs control). Addition of DHP to potassium-treated cultures resulted in no decrease in cell numbers $(102 \pm 12 \%$ of $\mathrm{KCl}$ alone; $n=6$ experiments; $p>0.05)$, whereas in sister cultures grown in normal potassium, DHP caused cell numbers to decrease by $68 \pm 2 \%$ ( $n=6$ experiments; $p<0.05$ vs untreated). Protection against pentobarbital toxicity was similar; $50 \mu \mathrm{M}$ pentobarbital nonsignificantly increased cell numbers by $31 \pm 24 \%$ in the presence of $\mathrm{KCl}(p>0.05$ vs $\mathrm{KCl}$ alone; $n=4)$, whereas it depressed neuronal numbers by $72 \pm 2 \%$ $(p<0.05 ; n=4)$ in normal medium.

Because elevated potassium protected against both spontaneous neuronal death and GABA-induced neuronal death, it is possible that the apparent protective effect of $\mathrm{KCl}$ is attributable to a factor related to the higher cell density produced by $\mathrm{KCl}$. For instance, the higher density of neurons in elevated potassium may result in the accumulation of paracrine trophic support that prevents GABA-induced toxicity. To test this idea, we plated neurons at one-third the normal seeding density to counteract the approximately threefold increase in cell numbers of KCl-treated cultures and examined the ability of $\mathrm{KCl}$ to protect against GABA toxicity. As shown in Figure $7, E$ and $F, \mathrm{KCl}$ still protected against DHP toxicity when the initial seeding density was decreased. Cell counts showed DHP-treated cultures numbered $94 \pm 16 \%$ of $\mathrm{KCl}$ alone-treated cultures $(p>0.05 ; n=3$ experiments).

Although these experiments suggest that elevated potassium rescues cells from $\mathrm{GABA}_{\mathrm{A}}$-induced neuronal death, the results do not indicate where in the death pathway depolarization might act to rescue cells. For instance, chronic depolarization may lead to presynaptic depolarization block (via inactivation of voltagegated sodium and calcium channels) and result in decreased endogenous $\mathrm{GABA}$ release, or $\mathrm{KCl}$ depolarization might act downstream of $\mathrm{GABA}_{\mathrm{A}}$ receptors to rescue cells, perhaps by raising postsynaptic intracellular calcium concentration.

To address the hypothesis that potassium protects neurons through an effect downstream of GABA receptor activation, we examined whether neuronal death mediated by direct activation of $\mathrm{GABA}_{\mathrm{A}}$ receptors was prevented by elevated potassium. We
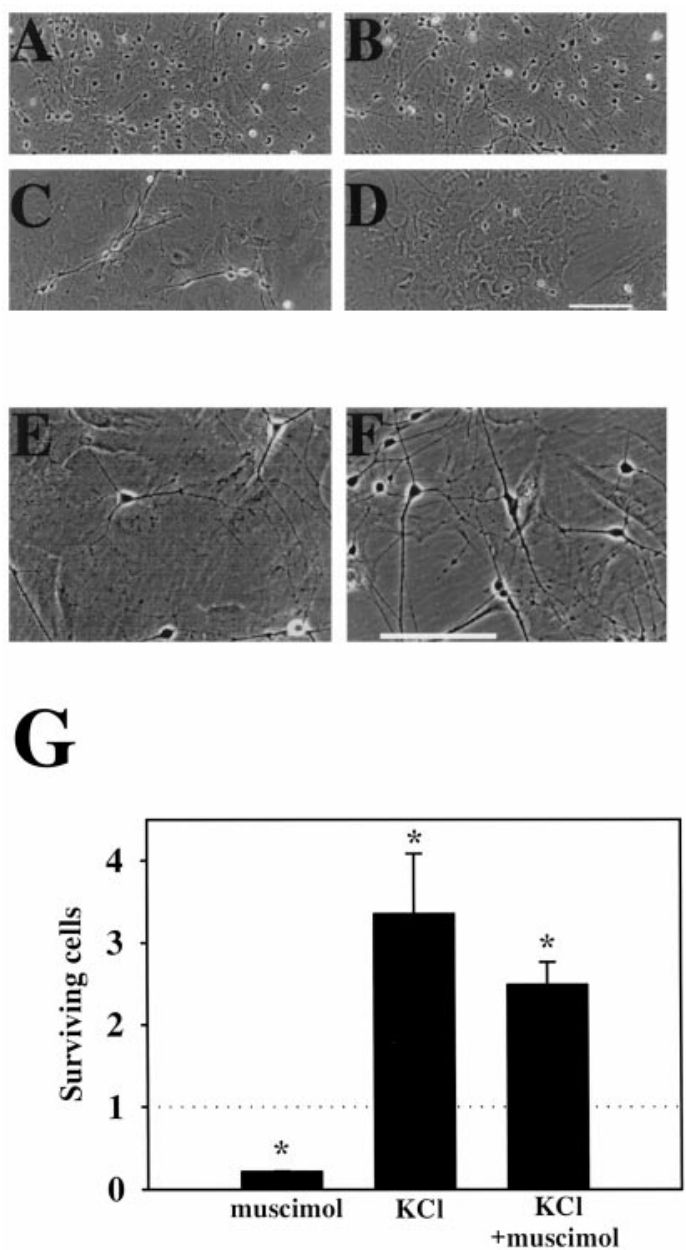

Figure 8. Neuroprotective effects of elevated extracellular potassium. A, Representative photomicrograph of a culture treated with elevated $\mathrm{KCl}$ ( $35 \mathrm{~mm}$ total) on DIV 4. B, Sister culture treated with $35 \mathrm{~mm} \mathrm{KCl}$ and 3 $\mu$ M DHP. $C$, Control culture grown with normal $(5 \mathrm{~mm})$ potassium. $D$, DHP-treated culture in normal potassium. $E, F$, Altered neuronal density does not explain the effect of elevated $\mathrm{KCl}$. Cells were initially plated at one-third the normal density and treated with either elevated extracellular potassium alone $(E)$ or elevated potassium and $3 \mu \mathrm{M}$ DHP $(F)$. Scale bars, $130 \mu \mathrm{m}$ (bar in $F$ applies to $C-F$; bar in $H$ applies to $G, H$ ). $G$, Effect of $\mathrm{KCl}$ on muscimol toxicity. Bars represent normalized neuronal counts of cultures treated with muscimol alone $(10 \mu \mathrm{M}), 35 \mathrm{~mm}$ potassium alone, or muscimol plus $\mathrm{KCl}(n=4$ experiments; all conditions, $p<0.05$ vs control; $p=0.06$ for $\mathrm{KCl}$ vs $\mathrm{KCl}$ plus muscimol conditions).

challenged cells with $10 \mu \mathrm{M}$ muscimol, which depressed cell counts at DIV 10-12 similarly to GABA potentiators (Fig. 8G). Figure $8 G$ shows that muscimol-induced neuronal death is indeed greatly reduced by maintaining cells in high-potassium growth medium. This result strongly suggests that the protective effect of $\mathrm{KCl}$ occurs downstream of $\mathrm{GABA}_{\mathrm{A}}$ receptor activation.

Elevated potassium is an indirect method of elevating intracellular calcium. It has been proposed, for instance, that alterations in potassium currents may be an important protective consequence of $\mathrm{KCl}$ elevation in other systems (Yu et al., 1997). To determine more directly whether elevated intracellular calcium participates in the protection provided to neurons from GABA toxicity, we co-treated cultures with Bay K 8644, an L-type calcium channel agonist. Treatment with Bay K $8644(1.5 \mu \mathrm{M})$ enhanced survival of control neurons (Fig. 9) and partially protected cells against muscimol-induced neuronal death (Fig. 9). 

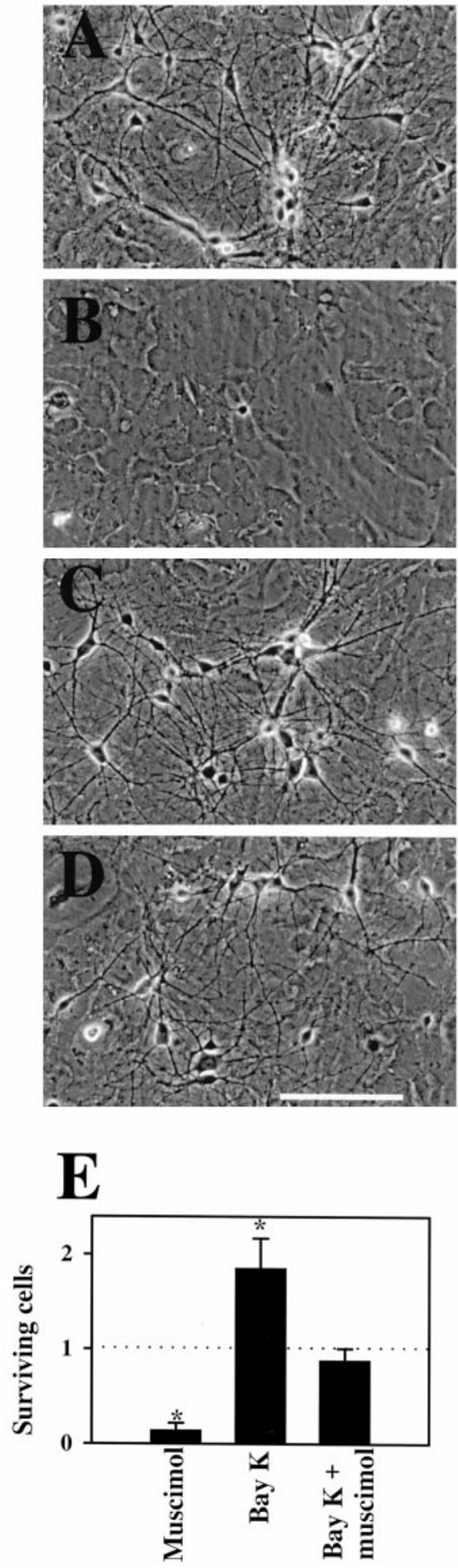

Figure 9. An L-type calcium channel agonist is neuroprotective. $A-D$, Representative fields from sister cultures $A$, Control culture. $B$, Muscimol $(10 \mu \mathrm{M})$-treated. $C$, Bay K $8644(1.5 \mu \mathrm{M})$. $D$, Bay K 8644 plus muscimol. $E$, Summary data representing cell counts from four independent platings assessed at DIV 8. Average cell counts from the Bay K 8644 treatment alone but not the Bay K 8644 plus muscimol group were significantly different from control ( $p=0.04$ and 0.31 , respectively; $n=6$ experiments). Cell numbers from the Bay K 8644 alone condition were also significantly different from the Bay K 8644 plus muscimol condition ( $p=$ 0.02 ), suggesting only partial protection by Bay K 8644 . Scale bar, $130 \mu \mathrm{m}$.
Neither the effect on normal cell death nor the protection against muscimol-induced toxicity was as pronounced as with $\mathrm{KCl}$ treatment (Figs. 8, 9), consistent with lower basal intracellular calcium increases produced by Bay K 8644 compared with $\mathrm{KCl}$ (Fig. 7B). These results make it likely that elevation of intracellular calcium has a direct role in the protective effects of $\mathrm{KCl}$ and Bay K 8644 treatments.

\section{DISCUSSION}

We have presented evidence that preventing endogenous GABA actions at $\mathrm{GABA}_{\mathrm{A}}$ receptors blocks a fraction of the neuronal death occurring normally in hippocampal cultures. Potentiation of $\mathrm{GABA}_{\mathrm{A}}$ receptors with neurosteroids or other classes of potentiators of $\mathrm{GABA}_{\mathrm{A}}$ receptors causes death of $\sim 80 \%$ neurons over the course of 1 week in vitro. The enhanced neuronal death is prevented by including antagonists of $\mathrm{GABA}_{\mathrm{A}}$ receptors in the culture medium. Chronic depolarization of cells with elevated extracellular potassium or direct facilitation of calcium influx inhibits the susceptibility of the neurons to GABA-induced death and promotes basal cell survival. These results suggest a new means by which neurons could be targeted for programmed cell death during development and may have important implications for mechanisms by which an important class of drugs, notable for both their clinical utility and abuse potential, may promote neuronal toxicity in the developing nervous system.

\section{Mechanism of GABA-mediated neuronal death}

The mechanism by which cells die by GABA toxicity in the current paradigm is unclear and will require further investigation. Hints may come from comparison with other models of neuron death. Sympathetic neurons subjected to nerve growth factor (NGF) deprivation die 2-3 d after withdrawal of trophic support. This cell death is prevented by high-potassium medium (Koike et al., 1989). In this model, protection has been correlated with elevated calcium, but NGF support does not apparently act by raising intracellular calcium, nor does NGF deprivation decrease intracellular calcium (Franklin et al., 1995). This may be in contrast to the present model, in which both the protection and demise of hippocampal neurons are associated with intracellular calcium levels.

The current model bears similarities to the cerebellar granule cell model of neuronal death (D'Mello et al., 1993). Cultured granule cells survive in the presence of elevated extracellular potassium and serum but die on decreasing potassium concentration to $5 \mathrm{~mm}$ and withdrawing serum. A notable difference between granule cell death and GABA-induced hippocampal cell death is that GABA protects against neurodegeneration induced by potassium and serum deprivation in cultures of cerebellar granule neurons (Castoldi et al., 1998).

The results of the present experiments are consistent with the hypothesis that both the demise and the rescue of hippocampal neurons depend on the level of intracellular calcium. By this hypothesis, $\mathrm{GABA}_{\mathrm{A}}$ receptor activation, by inhibiting depolarization, depresses calcium influx, enhancing the probability of neuronal death. Bicuculline, elevated potassium, and Bay K 8644 all protect neurons by tipping the balance toward excitation and elevated intracellular calcium. The depression of calcium influx in response to depolarizing challenges in DHP-treated cultures suggests that overactivation of $\mathrm{GABA}_{\mathrm{A}}$ receptors may produce longer-term changes in calcium entry or handling that may participate in the demise of the cells. The precise biochemical pathways responsible for neuronal death remain to be elucidated, 
and it is possible that depolarizing influences interact with other trophic signals to mediate survival in hippocampal cells (MeyerFranke et al., 1995). For instance, it has recently been suggested that NMDA-induced trophic actions in cerebellar granule cells is mediated by induction of BDNF expression (Bhave et al., 1999).

A previous study found that GABAmimetics cause retraction of the dendrites of cultured hippocampal neurons (Mattson and Kater, 1989). This result may be consistent with the limited neuritic arbors found in cells remaining after chronic GABAmimetic treatment in the present study. This previous study found no effect of GABAmimetics on cell survival. This is likely because of the shorter time frame in which survival was examined in the previous work. It is also possible that the use of postnatal neurons in the present study rather than embryonic neurons is an important difference if developmental issues contribute to the effects observed. Finally, it is possible that astrocytes in our postnatal cultures (and not present in many embryonic culture preparations) offer trophic or other support important to the effects observed in the present study.

\section{Relevance to neuronal death in vivo}

Although peripheral cells are acutely dependent on neurotrophic support, and CNS neurons are responsive to neurotrophic factors, the mechanisms of developmental neuronal death in the CNS are still unclear (Lewin and Barde, 1996). It is possible that neurotransmitter-induced cell death may play a role in normal developmental programmed cell death. Consistent with the idea that a proper balance between excitation and inhibition may help dictate final neuron numbers in the CNS, it was recently found that NMDA receptor antagonists promote increased apoptosis in CNS regions undergoing natural developmental programmed cell death (Ikonomidou et al., 1999). If GABA receptor activation per se participates in targeting cells for programmed cell death, the developmental switch in chloride gradient that occurs in many CNS regions may be important for targeting particular neurons for death.

Neurosteroids were used as neuromodulators of $\mathrm{GABA}_{\mathrm{A}}$ receptors because of the presence of these agents endogenously. In vivo, concentrations of neurosteroids are in the nanomolar range (Lambert et al., 1995). Our evidence (Fig. 2C) suggests that endogenous GABAmimetic neurosteroid concentrations in the bulk medium of hippocampal cultures are negligible. Regulation of the production and release of neurosteroids is relatively unexplored, although recent evidence suggests decreased levels of neurosteroids with clinical depression (Uzunova et al., 1998).

We found that other potentiators of $\mathrm{GABA}_{\mathrm{A}}$ receptors, notably barbiturates and benzodiazepines, also promoted neuronal death. These results have implications for acute and chronic use of these drugs and suggest that neuronal death may be a consequence of their prolonged use. Phenobarbital is a commonly used anticonvulsant in child neurology; therefore, understanding the in vivo conditions under which GABAmimetics may be neurotoxic is of prime importance. Note, however, that our experiments used benzodiazepines and barbiturates near their anticipated maximum concentrations, likely to represent anesthetic rather than anticonvulsant concentrations. Also, recent in vivo data showing GABA toxicity in intact rats suggest a developmental window for susceptibility to overinhibition-induced neuronal death (Ikonomidou et al., 2000). Therefore, GABA-induced neuronal death may be particularly relevant to chronic exposure to these drugs in utero or in the early postnatal period.

\section{REFERENCES}

Ankarcrona M (1998) Glutamate induced cell death: apoptosis or necrosis? Prog Brain Res 116:265-272.

Bhave SV, Ghoda L, Hoffman PL (1999) Brain-derived neurotrophic factor mediates the anti-apoptotic effect of NMDA in cerebellar granule neurons: signal transduction cascades and site of ethanol action. J Neurosci 19:3277-3286.

Castoldi AF, Barni S, Randine G, Costa LG, Manzo L (1998) Ethanol selectively interferes with the trophic action of NMDA and carbachol on cultured cerebellar granule neurons undergoing apoptosis. Brain Res Dev Brain Res 111:279-289.

Chen Q, Olney JW, Lukasiewicz PD, Almli T, Romano C (1998) $\mathrm{Ca}^{2+}$ independent excitotoxic neurodegeneration in isolated retina, an intact neural net: a role for $\mathrm{Cl}^{-}$and inhibitory transmitters. Mol Pharmacol 53:564-572.

Cherubini E, Rovira C, Gaiarsa JL, Corradetti R, Ben Ari Y (1990) GABA mediated excitation in immature rat CA3 hippocampal neurons. Int J Dev Neurosci 8:481-490.

Choi DW (1995) Calcium: still center-stage in hypoxic-ischemic neuronal death. Trends Neurosci 18:58-60.

Deshmukh M, Johnson Jr EM (1997) Programmed cell death in neurons: focus on the pathway of nerve growth factor deprivation-induced death of sympathetic neurons. Mol Pharmacol 51:897-906.

D'Mello SR, Galli C, Ciotti T, Calissano P (1993) Induction of apoptosis in cerebellar granule neurons by low potassium: inhibition of death by insulin-like growth factor I and cAMP. Proc Natl Acad Sci USA 90:10989-10993.

Franklin JL, Sanz-Rodriguez C, Juhasz A, Deckwerth TL, Johnson Jr EM (1995) Chronic depolarization prevents programmed death of sympathetic neurons in vitro but does not support growth: requirement for $\mathrm{Ca}^{2+}$ influx but not Trk activation. J Neurosci 15:643-664.

Grynkiewicz G, Poenie M, Tsien RY (1985) A new generation of $\mathrm{Ca}^{2+}$ indicators with greatly improved fluorescence properties. J Biol Chem 260:3440-3450.

Hasbani MJ, Hyrc KL, Faddis BT, Romano C, Goldberg MP (1998) Distinct roles for sodium, chloride, and calcium in excitotoxic dendritic injury and recovery. Exp Neurol 154:241-258.

Honegger P, Pardo B, Monnet-Tschudi F (1998) Muscimol-induced death of GABAergic neurons in rat brain aggregating cell cultures. Brain Res Dev Brain Res 105:219-225.

Hwang JY, Kim YH, Ahn YH, Wie MB, Koh JY (1999) N-Methyl-Daspartate receptor blockade induces neuronal apoptosis in cortical culture. Exp Neurol 159:124-130.

Ikonomidou C, Bosch F, Miksa M, Bittigau P, Vockler J, Dikranian K, Tenkova TI, Stefovska V, Turski L, Olney JW (1999) Blockade of NMDA receptors and apoptotic neurodegeneration in the developing brain. Science 283:70-74.

Ikonomidou C, Bittigau P, Ishimaru MJ, Wozniak DF, Koch C, Genz K, Price MT, Stefovska V, Horster F, Tenkova T, Dikranian K, Olney JW (2000) Ethanol-induced apoptotic neurodegeneration and fetal alcohol syndrome. Science 287:1056-1060.

Koike T, Martin DP, Johnson Jr EM (1989) Role of $\mathrm{Ca}^{2+}$ channels in the ability of membrane depolarization to prevent neuronal death induced by trophic-factor deprivation: evidence that levels of internal $\mathrm{Ca}^{2+}$ determine nerve growth factor dependence of sympathetic ganglion cells. Proc Natl Acad Sci USA 86:6421-6425.

Lambert JJ, Belelli D, Hill-Venning C, Peters JA (1995) Neurosteroids and GABAA receptor function. Trends Pharmacol Sci 16:295-303.

Leinekugel X, Khalilov I, McLean H, Caillard O, Gaiarsa JL, Ben-Ari Y, Khazipov R (1999) GABA is the principal fast-acting excitatory transmitter in the neonatal brain. Adv Neurol 79:189-201.

Lewin GR, Barde YA (1996) Physiology of the neurotrophins. Annu Rev Neurosci 19:289-317.

Macdonald RL, Olsen RW (1994) GABA A receptor channels. Annu Rev Neurosci 17:569-602.

Majewska MD (1992) Neurosteroids: endogenous bimodal modulators of the $\mathrm{GABA}_{\mathrm{A}}$ receptor. Mechanism of action and physiological significance. Prog Neurobiol 38:379-395.

Majewska MD, Harrison NL, Schwartz RD, Barker JL, Paul SM (1986) Steroid hormone metabolites are barbiturate-like modulators of the GABA receptor. Science 232:1004-1007.

Mattson MP, Kater SB (1989) Excitatory and inhibitory neurotransmitters in the generation and degeneration of hippocampal neuroarchitecture. Brain Res 478:337-348.

Meyer-Franke A, Kaplan MR, Pfrieger FW, Barres BA (1995) Charac- 
terization of the signaling interactions that promote the survival and growth of developing retinal ganglion cells in culture. Neuron 15:805-819.

Michaelis EK (1998) Molecular biology of glutamate receptors in the central nervous system and their role in excitotoxicity, oxidative stress and aging. Prog Neurobiol 54:369-415.

Uzunova V, Sheline Y, Davis JM, Rasmusson A, Uzunov DP, Costa E, Guidotti A (1998) Increase in the cerebrospinal fluid content of neurosteroids in patients with unipolar major depression who are receiving fluoxetine or fluvoxamine. Proc Natl Acad Sci USA 95:3239-3244.

Wittmer LL, Hu Y, Kalkbrenner M, Evers AS, Zorumski CF, Covey DF (1996) Enantioselectivity of steroid-induced gamma-aminobutyric
$\operatorname{acid}_{\mathrm{A}}$ receptor modulation and anesthesia. Mol Pharmacol 50:1581-1586.

Yang J, Thio LL, Clifford DB, Zorumski CF (1993) Electrophysiological properties of identified postnatal rat hippocampal pyramidal neurons in primary culture. Brain Res Dev Brain Res 71:19-26.

Yu SP, Yeh CH, Sensi SL, Gwag BJ, Canzoniero LM, Farhangrazi ZS, Ying HS, Tian M, Dugan LL, Choi DW (1997) Mediation of neuronal apoptosis by enhancement of outward potassium current. Science 278:114-117.

Zorumski CF, Mennerick SJ, Covey DF (1998) Enantioselective modulation of GABAergic synaptic transmission by steroids and benz[e]indenes in hippocampal microcultures. Synapse 29:162-171. 